\title{
Study of Five-level diodes-clamped Inverter Modulation Technology Based on Three-harmonic Injection Method
}

\author{
Xu Zheng ${ }^{1, a}$, Li Song ${ }^{2, b}$ and Pan Hongying ${ }^{3, c}$ \\ ${ }^{1,2,3}$ School of Electrical and Electronic Engineering, East China Jiaotong University, Nanchang \\ 330013, China \\ a187391733@qq.com, b26545175@qq.com, ‘951544346@qq.com
}

Keywords: voltage shifted modulation, clamping diode, five-level inverter

\begin{abstract}
With the development of high technology, inverter request higher capacity. However, the traditional two level inverter capacities of the power electronic devices have been difficult to achieve high power requirements. Therefore, the national science and technology workers continue to put forward a variety of excellent performance of new multilevel inverter topology. This paper introduces five-level neutral point clamped inverter topology structure, characteristic and working principle. The voltage shifted modulation technology in PWM IPD, POD and APOD three arrangements and principle are described in detail. Then a simulation study gave out three kinds of arrangement of current $\mathrm{i}_{\mathrm{A}}$, phase voltage $\mathrm{v}_{\mathrm{AN}}$ and line voltage $\mathrm{v}_{\mathrm{AB}}$ waveform and spectrum diagram. The simulation shows the three harmonic injection methods in five-level inverter application feasibility and correctness.
\end{abstract}

\section{Introduction}

In the past 20 years, the converter has been used more and more widely in the AC drive fields due to the energy saving, reliability and performance indicators of great advantage. The huge demand of high power converters in the industrial areas promotes the power electronic device capacity, voltage level and micro-electronic control technology to improve. Then all kinds of power converter topologies are constantly.

In 1980, Japan's Nagaoka Science and Technology University A. Nabae et al first proposed threepoint inverter, also called neutral point clamped inverter, NPC [1]. With the two-point type converter, it has many advantages [2]: (1) the turn-off voltage of power devices is only half of the DC bus voltage. In the same situation, the DC bus voltage can be doubled, and the capacity can also be doubled. So it can be widely used in large power converter; (2) In the same switch frequency and the control mode, three-point type converter output voltage or current harmonic considerably less than two point type converter, so its total harmonic distortion (THD) is far smaller than that of the two-point type converter; The three-point inverter input current waveform can guarantee a certain degree of sine even in very low switching frequency. The topology of the inverter has been widely used in the oil field, locomotive traction and other larger areas as well as in the electric power system of flexible power supply (FACTS).

This paper introduces voltage shifted modulation [3, 4] of five-level diode clamped inverter based on three-harmonic injection method in detail. And the simulation study proved that three-harmonic injection method in diode clamped five-level inverter sampling is correct and feasible.

\section{Diode-clamped five-level inverter topology and operation principle}

Diode-clamped five-level inverter main circuit topology structures as shown in Figure 1. Each bridge arm has eight switch tubes, the power device makes energy bidirectional flowing IGCT device. DC capacitor is composed of four like capacitors connected in series, led D1, D2, D3, D1 ', D2 ' and D3 ' called the clamp diode ( Clamping Diodes ), it can make the converter outputs five voltage waveforms: $0, \mathrm{E}, 2 \mathrm{E}, 3 \mathrm{E}$ and $4 \mathrm{E}$ five levels. In every moment, the converter must have four 
on-off tubes. To A state as an example, the possible switch tube are the combination of VT1 、 VT2 、VT3 and VT4, VT2、VT3、VT4 and VT1'、VT3、VT4、VT1' and VT2', VT4 、VT1' VT2' and VT3', VT1' VT2' ${ }^{\prime}$ VT3' $、$ VT4'. Any other combinations are not allowed. In the process of commutation in across two levels above the switch state is not allowed.

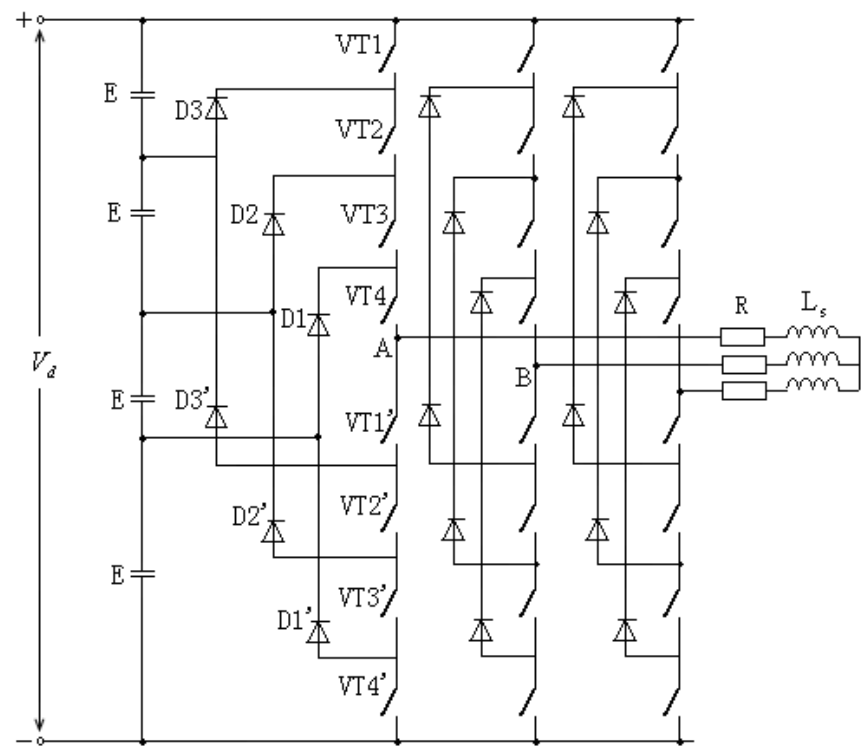

Fig. 1 Topology of four-level Clamping Diodes inverter

Besides previously mentioned advantages, Five level diode clamped inverter has the following advantages: (1) There is no dynamic pressure. Because the clamp diode is used, the converter need not consider the dynamic pressure. But the traditional two point type converter has to consider that. (2) It has very low harmonic distortion (THD). Converter phase voltage five level grade, relative to the two point type converter, it can be used to eliminate the harmonics of two degrees of freedom, so the harmonic distortion is very low; (3) It has very low electromagnetic interference ( Electro-Magnetic Interference, EMI ).

\section{Principle of Voltage Shifted Modulation}

Voltage shifted modulation is way based on the carrier modulation. If the DC side capacitor voltage is equal to four, the carrier number is $\mathrm{m}-1$ when five level diode clamped inverter level number is $\mathrm{m}$. all of these carriers have the same frequency and the same amplitude. This ( $\mathrm{m}-1)$ a triangular carrier in the space is distributed vertically, and the occupied area is continuous, with each other closely connected, symmetrically distributed on the horizontal axis on both sides, and then with a sinusoidal modulation wave are compared, to generate a trigger pulse.

Voltage shifted modulation mode have three kinds of pattern:(1) with phase array ( In-phase Disposition, IPD );(2)anti-phase arrangement ( Phase Opposition Disposition, POD ); (3)alternately reverse phase array ( Alternative Phase Opposition Disposition, APOD ). They work as shown in Figure 2 below. Due to limited space, this paper gives IPD simulation waveform, the remaining two simulations is basically the same as IPD.

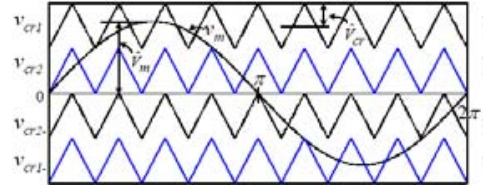

(a) Principle of IPD

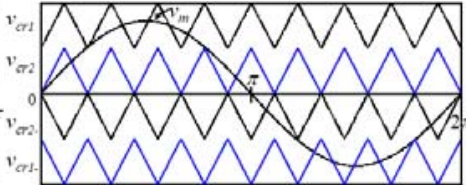

(b) Principle of POD

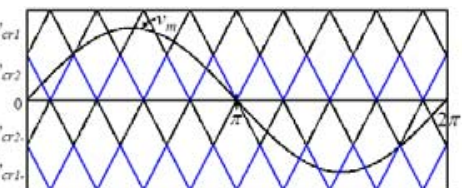

(c) Principle of APOD

Fig. 2 Principle of voltage shifted modulation

In Figure 2, at the moments of sine wave and triangular wave intersecting, if the modulation wave amplitude is greater than the triangle wave amplitude, it turned on at the corresponding switching devices, conversely, turned off the device. In the voltage shifted modulation technology 
we respectively define two parameters: a frequency modulation is $m_{f}$ and amplitude modulation is $m_{a} . m_{f}$ is equal to the carrier frequency and wave frequency modulation ratio; $m_{a}$ equal to the modulation wave peak and carrier peak ratio.

\section{Three-harmonic injection method}

Expression of Injecting three harmonic sinusoidal modulated signals is given as follows:

$$
\left\{\begin{array}{l}
v_{m A}=m \cdot \sin \left(\omega_{0} t\right)+k \sin \left(3 \omega_{0} t\right) \\
v_{m B}=m \cdot \sin \left(\omega_{0} t+120^{\circ}\right)+k \sin \left(3 \omega_{0} t\right) \\
v_{m C}=m \cdot \sin \left(\omega_{0} t+240^{\circ}\right)+k \sin \left(3 \omega_{0} t\right) \\
v_{m K}=k \sin \left(3 \omega_{0} t\right)
\end{array}\right.
$$

By formula (1), three-harmonic injection is adding a three harmonic signal $k \sin \left(3 \omega_{0} t\right)$ in the original three-phase symmetric positive signal. In order to avoid injecting three harmonic of modulation signal and the carrier, no overshoot phenomenon, amplitude $\mathrm{K}$ in the three harmonic signals must be between in 0.15 to $0.2[5,6,7]$.

\section{Simulation}

In order to study the specific situation of five level diode clamped inverter using IPD and arrangement of APOD phase voltage and line voltage waveform, and the size of contained the harmonic components, this paper uses Matlab/Simulink and Powersystem to model and simulate five level diode clamped inverter. Due to space limitations, here a specific structure model didn't given. Simulation parameters are as follows: frequency modulation is equal to 32; amplitude modulation is equal to 0.9 ; the operating frequency of the power supply is equal to $50 \mathrm{~Hz}$; DC side voltage $\mathrm{E}$ is equal to $100 \mathrm{~V}$; load is resistance-inductance series $\mathrm{R}=10 \Omega$; $\mathrm{L}=1 \mathrm{mH}$. Arrangement of IPD of phase voltage $\mathrm{v}_{\mathrm{AN}}$, line voltage waveform $\mathrm{v}_{\mathrm{AB}}$ and harmonic frequency $\mathrm{v}_{\mathrm{AN}} 、 \mathrm{v}_{\mathrm{AB}}$, respectively, as shown in Figure 3,4.

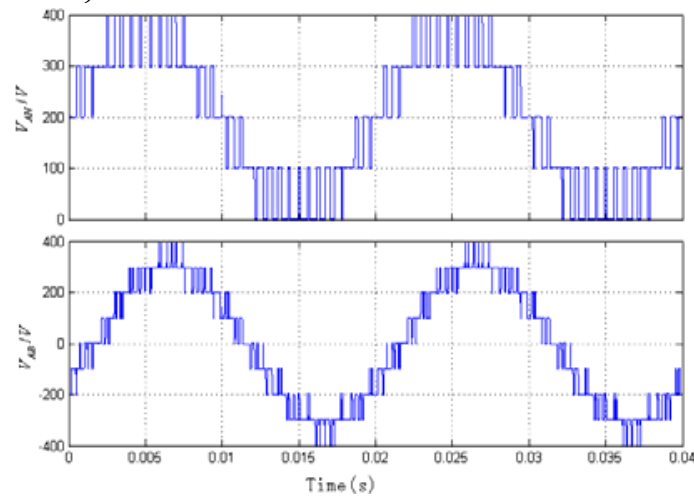

Fig.3 Simulation waveform of $\mathrm{v}_{\mathrm{AN}}$ and $\mathrm{v}_{\mathrm{AB}}$

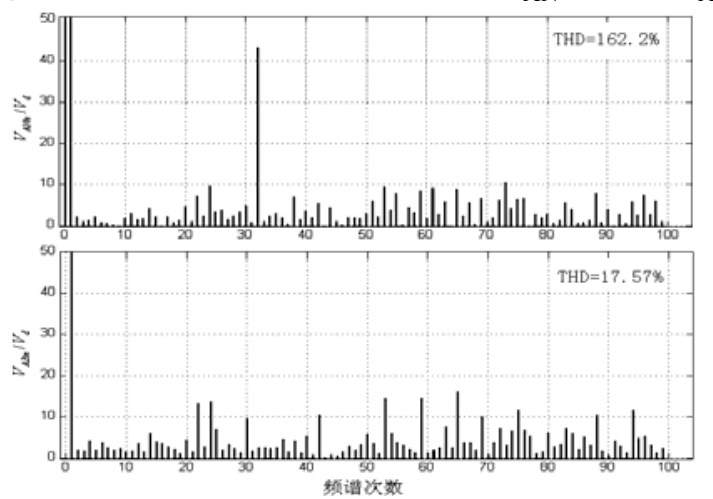

Fig. 4 Simulation harmonic spectrum of $\mathrm{v}_{\mathrm{AN}}$ and $\mathrm{v}_{\mathrm{AB}}$ 
By the simulation waveform, we can see that using voltage shifted modulation total THD of diode clamped five level inverter is relatively small, but for whether the phase voltage $\mathrm{v}_{\mathrm{AN}}$ or the line voltage $\mathrm{v}_{\mathrm{AB}}$, the waveform is in $n \mathrm{f}_{\mathrm{c}}$ as the center, to the two sides to symmetric distribution between $\pm\left(k f_{0}+B\right)$. We can find by the simulation waveform, due to diode clamped five level inverter phase voltage $\mathrm{v}_{\mathrm{AN}}$ is from $0 \mathrm{~V}$ to $400 \mathrm{~V}$ changes, $\mathrm{v}_{\mathrm{AN}}$ waveform superimposed on the DC component, resulting in the waveform symmetrical, so the THD of $\mathrm{v}_{\mathrm{AN}}$ is greater than 1 . The waveform of $\mathrm{v}_{\mathrm{AB}}$ is positive and negative periodic symmetric, so THD of $\mathrm{v}_{\mathrm{AB}}$ without filtering under the condition of only $17.57 \%$. For diode clamped multilevel inverter which is a need to pay attention to.

\section{Conclusion}

Five-level diode-clamped inverter can make THD of the network side very low, and the power factor close to 1 . This power factor adjustable PWM inverter can also be modulated by varying the ratio of the ways to control the active power and reactive power, so the topology structure has very high practical value. The inverter has been widely applied in the oil field, locomotive traction and FACTS industries.

\section{References}

[1] A. Nabae, I. Takahashi, and H. Akagi, A New Neutral-Point-Clamped PWM Inverter, IEEE Trans. On Industry Application [J], Vol. 17, No. 5 (1981), p. 518-523

[2] Zhan Changhua, Qin Quanhua, Han Yingduo et. Study on Mathematical Model and System Simulation of the There-level PWM Reversible Rectifier [J], Proceedings of the CSEE, Vol. 19, No. 7 (1999), p. 45-48

[3] G. Carrara, S. Gardella, M. Marchesoni, R. Salutari and G. Sciutto, A New Multilevel PWM Method: A Theoretical Analysis, IEEE Trans. On Power Electronics[J], Vol. 7, No. 3(1992) p. 497-505

[4] Wu Bin, Song Pinggang. Comprehensive Analysis of Multi-Megawatt Varible Frequency Drives[J], Transaction of China Electrotechnical Society, Vol. 19, No. 8, p. 40-52

[5] Yang Hong, Ruan XinBo, Yan Yangguang. PWM Control of a Four-Leg Three-Phase Inverter [J]. Journal of Nanjing University of Aeronautics \& Astronautics. Vol. 34, No. 6(2002), p. 575-579.

[6] Zhang R, Boroyevich D, Prasad V H. A three-phase inverter with a neutral leg with space vector modulation[C]. In:Conference Record of IEEE APEC(1997), p. 851-863

[7] Jahns T M, De Doncker R E. System design considerations for a high-power aerospace resonant link converter[J]. IEEE Trans Power Electron(1993), p.663-671 